\title{
CIDADANIA NACIONAL E EUROPEIA NA EDUCAÇÃO: UM OLHAR A PARTIR DO CONTEXTO PORTUGUÊS
}

\author{
Sara Pinheiro ${ }^{1}$ \\ Eunice Macedo ${ }^{2}$ \\ Centro de Investigação e Intervenção Educativas (CIIE) da Faculdade de \\ Psicologia e de Ciências da Educação da Universidade do Porto (FPCEUP)
}

\section{RESUMO}

O debate sobre cidadania nacional e europeia insere-se nas práticas contemporâneas das sociedades da União Europeia (UE) e do mundo global, além da Europa. A sua relação com a educação assenta numa lógica interativa que se diz direcionada à partilha de perspetivas. Ao nível político o discurso de incentivo do respeito e a aceitação da diversidade na busca de uma UE unida na sua pluralidade cultural conflitua-se com políticas de cariz exclusor e de limite à cidadania. Após um enquadramento histórico, este artigo analisa documentos nacionais e da UE, que se referem às e aos jovens, pensando numa cidadania ativa, com voz e participação. Procuramos também compreender como a história da UE tem vindo a contribuir para o debate da cidadania europeia. $\mathrm{O}$ estudo $^{3}$ na base deste artigo está a ser desenvolvido com jovens dos 15 aos 25 anos que frequentam uma Escola Profissional no Norte de Portugal.

Palavras-chave: Cidadania nacional; cidadania europeia; escola; jovens; história da UE

\section{NATIONAL AND EUROPEAN CITIZENSHIP IN EDUCATION: AN INSIGHT FROM THE PORTUGUESE CONTEXT}

\begin{abstract}
The debate on national and European citizenship is part of contemporary practices of the European Union(UE) and beyond. Its relationship with education is based on an interactive logic that says to be directed at the sharing of perspectives. At the political level, the discourse on respect and acceptance of diversity in the pursuit of a united EU in its cultural diversity is in conflict with policies that exclude and limit citizenship. After setting out an historical framework on the European Union, this article examines national and UE documents, which refer to young women and men, with a view to active citizenship, with voice and participation. We try to understand how the history of the European Union has contributed to the debate on European citizenship. The study on the basis of this article is developed with young adults aged 15 to 25 years who attend a Vocational School in Northern Portugal.
\end{abstract}

Key words: National citizenship; European citizenship; school; young adults; EU history 


\section{Introdução}

Pensando o debate sobre cidadania nacional e europeia, importa enquadrar a construção e evolução da UE para compreender o caminho que se tem vindo a traçar e a respetiva contextualização histórica, social, económica como pilares estruturantes da cidadania europeia (CE). Queremos com isto dizer que importa compreender o conceito de CE à luz da (re)construção contínua da UE.

Procedendo a uma contextualização histórica da atual UE, esta nasceu a 9 de maio de 1950, com Robert Schuman - após a Segunda Guerra Mundial, num momento em que os países precisavam de se (re)unificar e reunir estratégias que permitissem o crescimento económico, social e a coesão política. Foi com o Tratado de Paris, assinado em 1951, que se instituiu a Comunidade Europeia do Carvão e do Aço (COMISSÃO EUROPEIA, 2013; MACEDO \& FERREIRA, 2014). A partir desta data os países que se uniram foram implementando medidas sucessivas que levaram aquilo que se considerava a evolução da Comunidade Europeia. Foi com esse objetivo que o Tratado de Roma, em vigor em 1958, deu origem à conhecida CEE (Comunidade Económica Europeia) denotando-se, desde logo, a prevalência da preocupação económica sobre as dimensões de coesão social e política.

A partir da década de 80, a Comunidade Económica Europeia começou a organizarse para o que viria dar origem à União Europeia (UE). A criação do mercado único (ou mercado interno europeu) implicou a abolição de grande número de barreiras de cariz técnico, jurídico e burocrático que impediam tanto o comércio livre como a livre circulação entre os países da UE. Esta nova dinâmica levou à expansão dos negócios das empresas, já que o reforço da concorrência, contribui para baixar os preços dos produtos e aumentar as possibilidades de escolha dos consumidores. Para além da circulação de capitais, o mercado único veio a permitir a livre circulação de pessoas, bens e serviços no interior da Europa, como se tratasse de um único país. Parecia assim abrir-se a promessa de uma Europa mais unida, com desenvolvimento e coesão social que, nos dias de hoje, cabe questionar.

Foi, posteriormente, com o Tratado de Maastricht (estabelecido em 1992 e em vigor desde 1993) que se estabeleceu a denominada União Europeia. Foi formalmente instituída a cidadania europeia, reforçados os poderes do Parlamento Europeu e criada a União Económica e Monetária (ibidem).

Este conjunto de tratados, e outros que não cabe aqui referir, têm permitido estabelecer o que a UE defende como princípios estruturantes para o diálogo entre os países que a constituem. As políticas educativas são disso exemplo, uma vez que a investigação mostra que "o impacto europeu nas políticas educativas dos estados obriga a reconhecer a influência crescente da União Europeia nas políticas educativas por toda a Europa" (MACEDO, 2011:20). Tendo em consideração que o tema que se traz para esta discussão assenta nas intenções políticas e suas possibilidades na cidadania e cidadania europeia, esta contextualização histórica da UE permite-nos compreender a sua relação com a cidadania europeia, uma vez que a UE se tem tornado cada vez mais relevante nas discussões sobre o futuro da cidadania (PREUSS et al., 2003). Se a UE diz defender a integração entre estados e os princípios de cidadania, esta integração europeia representa um desafio que tem implicações para o significado atual de democracia (ibidem). Parece poder dizer-se que as relações de poder entre estados, muito ligadas à economia, poderão estar a por em causa os direitos de cidadania que a Europa tem vindo a proclamar. Diferentes estados membros têm vindo a questionar o funcionamento da União Europeia a qual tem também sido fragilizada por acontecimentos como os ataques terroristas e o 
crescimento, consequente, de um clima de medo, tensão e instabilidade política e social. A saída da UE pelo Reino Unido é também exemplo do clima de instabilidade que se vive. Iniciada como a promessa de uma Europa unida que protegeria as e os cidadãos, parece que se acentuam hoje mais as fronteiras da Europa e que surge a necessidade de reconsiderar quer o modelo Europeu quer a promessa de cidadania que a ele tem sido associada.

Se a discussão da cidadania ganha espaço a nível nacional tem vindo também a ganhar espaço no debate europeu sobre cidadania europeia e no contexto mais amplo em que a cidadania é reconcetualizada para tentar incorporar as realidades de vida das e dos sujeitos. Nesse quadro, o debate da cidadania tem que transcender o contexto nacional e europeu e fazer sentido num contexto de mobilidade internacional, particularmente no que concerne à população brasileira dada a forte mobilidade da população do Brasil para Portugal. Esta tem sido justificada, na história mais recente, pela existência de uma língua comum que facilita a inserção do contexto português e uma maior aproximação à cidadania portuguesa e europeia ${ }^{4}$.

Na Europa, tal como no Brasil e noutros contextos desafiados pela consecução da cidadania, a relação entre as sociedades atuais e as/os sujeitos reflete as dinâmicas de globalização, em que se integra a discussão da educação e da cidadania nacional e europeia. Em Portugal, com a Lei de Bases do Sistema Educativo ${ }^{5}$ (ASSEMBLEIA DA REPÚBLICA, 1986), a educação para a cidadania começou a ser vista, nas políticas de cidadania ao nível nacional, como um

analisador privilegiado (...) [e] tem vindo, progressivamente, a ganhar espaço nos discursos políticos, normativos e sociais, (...) alcançou um estatuto de grande centralidade nas políticas educacionais de final (...) do século XX e primeira metade do século XXI (LEITE, FERNANDES \& SILVA, 2013, p.37).

No que concerne à escola e à educação, se é sabido que estas "deveriam ser promotoras de importante processo formativo para a desalienação e construção do sentido universal da cidadania numa perspectiva democrática (...) [em determinados períodos e contextos, estas parecem acabar por fornecer] à maquinaria capitalista o instrumental necessário para a sua manutenção e desenvolvimento, a despeito de significativas modificações no contexto das políticas públicas educacionais elaboradas e implementadas para fazer valer o direito de todos e para todos" (OLIVEIRA \& LIMA, 2013: p. 90).

$\mathrm{Na}$ história da educação, em Portugal, desde o início deste milénio, há que distinguir a existência de diferentes períodos, num vaivém entre a preocupação com uma maior inclusão social e a cidadania, e a preocupação com a inserção no mercado do trabalho. Focando o abandono escolar precoce, MACEDO et al (2015), referem três períodos distintos na educação (2000 a 2004; 2005 a 2010; e 2011 a 2014) fortemente influenciados pelas opções políticas dos partidos na governação, e pelas visões de cidadania a ela associadas.

Feita a contextualização histórica, este texto debate agora o modo como o conceito de cidadania nacional e europeia tem vindo a ser utilizado em documentos oficiais, com o intuito de questionar a articulação entre as intenções políticas e as possibilidades de desenvolvimento da cidadania na escola, como se referiu. O conceito de cidadania nacional e europeia tem vindo a conquistar lugar a nível político, social e educativo na sociedade portuguesa, em contexto europeu e global. Constitui pois um desafio para o ensino secundário profissional. Esta via educativa inclui tanto jovens que buscam uma formação 
profissionalizante como jovens com um percurso conturbado de abandono e de insucesso escolar. Este nível educativo, em Portugal corresponde aos últimos três anos do ensino médio, no Brasil. Os jovens são encaminhados para uma dupla certificação de ensino secundário (nível de escolaridade obrigatória) e de qualificação profissional. É uma via educativa mais orientada para o mercado de trabalho, como alternativa à via científico humanística do ensino regular, vocacionada para o prosseguimento de estudos pós secundários, na universidade ou nos cursos politécnicos.

Sendo necessário explicitar perante as e os jovens o papel fundamental de uma participação ativa e reflexiva no exercício da cidadania nacional e europeia no quotidiano, é pertinente analisar documentos, construídos na rede política nacional e europeia. Estes constituem um ponto de partida para estabelecer pontes com o contexto em estudo, frequentado por jovens de diferentes origens socio culturais e étnicas. É neste sentido que, com base na análise dos documentos, se procurará posteriormente compreender as perspetivas de jovens de etnias não-dominantes, atendendo a que se a etnia se relaciona com modalidades de pertença cultural (Council of Europe, 2008), pode também representar uma "nova" forma de desigualdade, a par da dimensão de classe social e do género (CasaNova, 2001).

Como pressuposto, ou horizonte desejável, das sociedades atuais, a busca de cidadania justifica o objetivo global de investir no desenvolvimento da educação para a cidadania, junto de populações jovens. Que sentidos de cidadania nacional e europeia

podemos encontrar em documentos nacionais e europeus? É para responder a esta questão que analisamos o estudo Menos Estado Social, uma Escola mais Desigual, de Ana Benavente e Paulo Peixoto (2015) que questiona as políticas do último governo de direita (2011-2015), em Portugal, no que diz respeito ao empobrecimento da escola pública e à sua falta de capacidade para dar resposta às necessidades sociais e educativas. Foca-se também o documento A Educação para a Cidadania na Europa que, numa visão comparativa entre os países europeus, analisa as políticas e as estratégias nacionais (EURYDICE, 2012); e o relatório Social Justice in the UE - Index Report 2015, de Daniel Schraad-Tischler, o qual compara os diferentes países da UE, analisando o índice de justiça social numa perspetiva evolutiva. A secção seguinte faz o enquadramento académico e político da discussão da cidadania nacional e europeia; a que se segue um olhar reflexivo a documentos-chave.

\section{Linhas do debate académico e político, em torno da cidadania e da cidadania europeia}

A cidadania pensada enquanto democracia, e enquanto garantia de direitos políticos, civis, sociais, económicos e culturais (SANTOS, 2014) permite estabelecer uma interligação entre cidadania e cidadania europeia como realidade que se pretende mais próxima, num contexto global. Apesar da cidadania ser um conceito com uma desconcertante diversidade de interpretações, poderia admitir-se que a cidadania europeia, em democracia, tem potencial para ampliar a cidadania ao nível nacional, uma questão que os desequilíbrios económicos e sociais entre estados membros obriga a questionar. Num período histórico anterior à crise europeia e mundial, MEIER \& LOMBARDO (2008) foram para além da discussão dos direitos da cidadania europeia na democracia, para argumentar que aquela opera em vários sentidos e assume diferentes significados, não se podendo debater a partir de uma abordagem única. Na mesma linha, KEATING (2009) referia que a cidadania europeia é um conceito que vai além de um conjunto de direitos e deveres, relativos à convivência entre pessoas de origens distintas tendo, para além disso, 
como objetivo desenvolver uma união entre cidadãos/ãs, através das suas culturas, valores, competências educativas e perspetivas para o futuro.

Havendo preocupação com a construção da cidadania, ganha sentido o foco numa educação em cidadania que opere a distintos níveis. Por um lado, deve, permitir a reflexão sobre direitos e deveres, nos quais os/as jovens se poderão rever (ou não), e por outro lado deve estimular a (inter)relação com os países 'vizinhos' europeus, permitindo estabelecer pontes para a interculturalidade a um nível mais global. Num mundo que se pretende intercultural, ser cidadão/ã é também ter direito a manter as diferenças culturais na esfera pública (ANSION \& TUBINO, 2007) a que as questões étnicas estão associadas; sendo que a efetivação da democracia depende do potencial interventivo e participativo das e dos sujeitos.

Neste quadro, a escola pode representar um papel fundamental para fomentar a democracia e das vivências interculturais. Como espaço que gere histórias de vida (LEMOS, CRUZ \& SOUSA, 2014), por um lado, pode permitir, respeitar e valorizar as diferenças individuais e de grupo, e, por outro, pode gerar a construção de novas histórias de vida, com democracia e cidadania. Assim, o debate sobre cidadania europeia (CE) é também um debate sobre educação e sociedade, que requer e reclama a participação com voz e que desafia a diversidade (MACEDO, 2011). De forma enriquecedora são colocadas perante uma nova 'luz' questões como igualdade, justiça social e inclusão, que se tornam relevantes na educação (ARNOT, 2009; ARAÚJO, 2007) e na compreensão da CE.

Pensar em cidadania europeia significa refletir sobre as políticas europeias dirigidas ao debate sobre cidadania nacional e europeia. Esta constitui um desafio à compreensão do paradigma de cidadania, enquanto congruência entre os direitos de um estado-nação e dos membros que o formam (OLSEN, 2013). Vários estudos atribuem o desenvolvimento da CE ao Tratado de Maastricht (MANTU, 2013), pois este permitiu à União Europeia a integração política, reforçando poderes ao nível do Parlamento Europeu (PE) e da criação da União Económica e Monetária (UEM), como se referiu acima. Tendo em consideração que o Tratado de Maastricht foi muito relevante, este marco não constituiu o ano zero nos discursos sobre cidadania na UE. Estas preocupações podem enraizar-se no final da Segunda Guerra Mundial (1941-1944) e na necessidade de construção de uma união europeia, inicialmente focada nos aspetos económicos (Comunidade Económica Europeia - CEE) e posteriormente, ampliada a outros aspetos da vida social, incluindo a cidadania ${ }^{6}$ (União Europeia - UE) (MACEDO \& FERREIRA, 2014; MANTU, 2013).

Salienta-se no entanto, que o conceito de CE, cujos sentidos se tem vindo a alterar em termos históricos e contextuais, vai além de um conjunto de direitos e deveres que compõem a convivência entre pessoas de origens distintas que se coadunam em determinadas situações ou oportunidades de vida. Trata-se de um conceito que assenta numa contínua (re)edificação (MANTU, 2013). Certos estudos apontam que para além de tratados, políticas e práticas que afetam o status dos sujeitos, a análise da cidadania na integração europeia desenvolve, a posteriori, conceções que permitem a cidadania na União (OLSEN, 2013). STOER (2008) a par com outros autores/as (como YOUNG 1990, 1997) sustentam a perspetiva de que a cidadania necessita de ser percecionada de forma plural, abarcando os olhares e as vozes das pessoas cidadãs interventivas nas práticas de cidadania. As perspetivas de Stoer e Iris Young abriam já portas à construção da cidadania europeia pois advogavam a necessidade de novos contratos sociais que passassem pela abertura à pluralidade de grupos sociais, de tal modo que as diferenças culturais, sociais ou étnicas caracterizassem os grupos, na sua forma de viver (YOUNG, 1990) mas que as suas diferenças não se constituíssem em desigualdades. Olhando ao historial da União Europeia e ao horizonte atual parece poder afirmar-se que alguns destes horizontes estão hoje muito 
aquém de realizados. Vejamos o que podemos induzir de documentos-chave ao nível europeu e nacional.

\section{Um olhar reflexivo a documentos-chave}

Na história mais recente da educação, um conjunto amplo de documentos oficiais, produzidos na UE, como a Estratégia de Lisboa (EUROPEAN COUNCIL, 2000), o White Paper on Intercultural Dialogue (COUNCIL OF EUROPE, 2008); Europe 2020 (COM, 2010), o Strategic framework for education and training (EUROPEAN COMMISSION, 2010) entre muitos outros cujo aprofundamento não cabe no âmbito deste artigo, vêm dar enfâse à relação entre cidadania europeia e nacional de uma forma complementar, entendendo que uma não substitui a outra (MACEDO \& FERREIRA, 2014). Torna-se relevante pensar a cidadania nacional e europeia à luz de análises nacionais e europeias, compreendendo as linhas de conciliação ou de distanciamento de perspetivas distintas. Neste ponto damos relevo a três documentos que consideramos essenciais. Começamos com um documento de âmbito nacional para passar a documentos produzidos ao nível europeu.

\section{Menos Estado Social, uma Escola mais Desigual, em foco}

O último estudo do Observatório de Políticas de Educação e de Formação, Menos Estado Social, uma Escola mais Desigual, de Ana Benavente e Paulo Peixoto (2015) questiona o modo como a governação dos últimos anos coloca em défice a Educação para a Cidadania. Acusa o Governo de procurar fomentar uma "escola instrumental, produtora de pessoas passivas, vistas como mão-de-obra mais ou menos qualificada, os célebres "recursos humanos" (BENAVENTE \& PEIXOTO, 2015, p.3) ou "capital humano" vendável ao nível europeu (MACEDO, 2011, p.34). BENAVENTE \& PEIXOTO permitem refletir que se a "escola não pode tudo quanto às desigualdades sociais" (2015, p.4; ver também FREIRE, 2002) pode e deve atuar sobre elas, através de políticas e de práticas que reflitam acerca das realidades das e dos jovens e que colaborem para a construção da sua cidadania, tendo em conta o seu ponto de partida, muitas vezes, desigual.

Mantendo a tendência histórica de exclusão através da educação, prevaleceu até 2015, uma escola desigual, assente na competição, a par de práticas governamentais de contenção de custos, em que não se equacionam as desigualdades sociais, cabe pois questionar, nas nossas escolas, a relação de distanciamento à educação para a cidadania e a ainda mais longínqua relação com a educação em cidadania europeia. Este aspeto contraria as orientações europeias para estimular a cidadania (MACEDO, 2011) através da educação e mais concretamente da escola. Acredita-se, no entanto, que fomentar a cidadania nacional e europeia e as práticas de cidadania é um desafio que se coloca, como tema e prática que se pretende de acesso comum às pessoas jovens. $\mathrm{O}$ caminho até às e aos jovens não é uniforme dada a heterogeneidade interna deste grupo social que condiciona a forma como cada jovem acolhe a diversidade (YOUNG, 1997) e reconhece a diferença. Esta perspectiva está em conformidade com STOER (2008) que clarifica a cidadania como forma plural, que deve promover a partilha de olhares próprios. Há pois que ter em conta em cada jovem as suas especificidades, o seu meio de origem, género e etnia, especificidades estas que podem estar associadas a maiores ou menores riscos e dificuldades na educação, potenciando diferentes formas de relação com a cidadania nacional e a cidadania europeia. 


\section{Analisando A Educação para a Cidadania na Europa à luz do contexto nacional}

Tal como outros documentos europeus, o documento A Educação para a Cidadania na Europa norteia a aplicação da cidadania, na "aprendizagem pela prática" (EURYDICE, 2012, p.3) abrindo espaço à intervenção em contexto escolar, pode também articular-se com a busca de implementação de uma cidadania ativa (PINTASILGO, 2012). Este documento constata, em diferentes países da UE, um investimento em determinados aspetos da cidadania com a finalidade de desenvolver a educação para a cidadania. A análise destes aspetos pode ser relevante, para além da Europa, pois a cidadania ativa, quer a nível nacional quer europeu ou global, pode considerar-se sustentada no "desenvolvimento da literacia política", associada ao "conhecimento dos factos básicos e compreensão dos conceitos essenciais"; à "aquisição de espírito crítico e de competências analíticas", associada a um pensamento mais crítico e reflexivo; ao desenvolvimento de "valores, atitudes e comportamentos" como respeito, tolerância, solidariedade; e ao incentivo "à participação ativa e à intervenção a nível da escola e da comunidade" (EURYDICE, 2012, p.28).

Nesse sentido, a garantia de cidadania e a educação para a cidadania nacional e europeia, na escola média, devem constituir uma realidade cada vez mais transversal às áreas curriculares e extracurriculares. Contrariamente, à afirmação da educação para a cidadania como "disciplina autónoma obrigatória" (EURYDICE, 2012, p.19), em Portugal sendo esta disciplina introduzida a partir dos 6 anos de idade, não tem esse carácter. Sendo a educação para a cidadania uma prática autónoma de cada país da União Europeia (UE), de acordo com o DECRETO-LEI N.¹39 (2012, p.3476)

a educação para a cidadania enquanto área transversal [é vista como] (...) passível de ser abordada em todas as áreas curriculares, não sendo imposta como uma disciplina isolada obrigatória, mas possibilitando às escolas a decisão da sua oferta nos termos da sua materialização disciplinar autónoma.

Já o DECRETO-LEI N. ${ }^{\circ}$ 91, de 2013, reduz a área de cidadania a oferta complementar, de par com áreas artísticas, culturais, científicas ou outras, a ser desenvolvida apenas no $1^{\circ}$ ciclo do ensino básico ${ }^{7}$. Isto mostra um claro desinvestimento do Estado português na educação para a cidadania, contrariando as recomendações europeias.

Particularmente nos últimos anos, face à dificuldade nacional para implementar cidadania e educação para a cidadania nacional e europeia, a proposta de desenvolvimento do Currículo Europeu incluindo a promoção da consciência Europeia e a influência da UE nas políticas da educação nacional (NÓVOA, 1996) continua atual e necessária. Permitiria o crescimento de uma perspetiva reflexiva e crítica, num enquadramento de reconhecimento das cidadanias jovens na educação (MACEDO \& ARAÚJO, 2014). No contexto português, apesar das escolas terem flexibilidade para articular e diversificar as ofertas, no que toca à educação para a cidadania e para a cidadania europeia, o papel autónomo que lhes é atribuído está sujeito às dificuldades económicas e políticas sentidas pela sociedade em geral. Em momentos de crise política e/ou económica as práticas de educação para a cidadania nacional e europeia ressentem-se nas nossas escolas. Esta dificuldade é ampliada ao contexto europeu e global, uma vez que, embora KEATING (2009) reforce que a cidadania europeia deve permitir o desenvolvimento de culturas, 
valores e perspetivas futuras, perante cenários de dificuldades económicas, sociais e políticas, os laços da cidadania confrontam-se com problemas contextuais e enormes fragilidades.

\section{Justiça social na EU, que condições para as pessoas jovens}

O relatório Social Justice in the EU - Index Report 2015 (SCHRAAD-TISCHLER, 2015) desoculta também que as condições sociais para a participação democrática das pessoas jovens em tempo de crise na UE tem sofrido um decréscimo comparativamente a períodos económicos e políticos mais estáveis e favoráveis. Como aí se refere, os períodos de instabilidade política e económica trazem consigo carências de participação democrática e uma diminuição das políticas pensadas para as populações jovens, diminuindo a promoção de ideologias democráticas e de participação na cidadania nacional e europeia. O relatório reforça que o fosso entre os países do norte e do sul da Europa é enorme, principalmente em períodos de crise, verificando-se que as taxas de pobreza e exclusão social crescem à medida que decresce o índice de justiça social.

De acordo com ARAR (2015) a justiça social deve incluir a justiça distributiva, associativa e cultural e nesse sentido, compreende-se a importância a atribuir à justiça social, sendo também necessário reconhecer a interdependência entre subsistemas sociais, que incluem a educação. BERKOVICH (2014) defende também um ponto de vista sócioecológico para que a justiça social em educação possa interligar-se com meios sociais mais amplos e permitir ações de liderança complementares, com a finalidade de desenvolver a justiça social nos diferentes níveis de educação. Pode pois admitir-se a forte articulação entre justiça social e educativa e o exercício da cidadania nacional e europeia.

Não se pode portanto, dissociar a justiça social da prática da cidadania nacional e europeia, sendo neste sentido que as políticas europeias e nacionais se devem dirigir, enquadrando a/s diferença/s individuais e de grupo numa sociedade que se pretende comum; ideia que pode relacionar-se com a argumentação em favor da manutenção das diferenças culturais na esfera pública, em linha com ANSION e TUBINO (2007). Com o contributo da educação, a cidadania nacional poderia ser construída no reforço da relação com a cidadania europeia (CE), como forma de construir o compromisso com uma união política na UE; uma estrutura supranacional que coloca a educação para a cidadania europeia nas agendas políticas.

Nesta linha, em conformidade com a teorização de SANTOS (2014), argumentamos acerca da necessidade da cidadania nacional e europeia assentarem num conjunto de direitos, orientados para os quotidianos das e dos sujeitos. Enfatiza-se a dimensão de participação, competindo à escola assumir o seu papel fundamental de construção coletiva "com participação democrática de todos[as] os[as] interessados" (RUSSO, 2014, p.70).

\section{Linhas conclusivas}

Partindo da evolução histórica da União Europeia, neste artigo discutimos cidadania nacional e europeia numa perspetiva de busca de inclusão das realidades de vida das e dos sujeitos. Concebe-se a cidadania nacional e europeia como processo de construção individual e coletivo assente na participação ativa e reflexiva, que incorpora direitos e deveres das e dos cidadãs/ãos, tendo em atenção as suas particularidades e diferenças. A perspetiva de construção histórica da União Europeia (UE) permite compreender que esta diz ambicionar a construção da cidadania europeia (CE) através da 
educação e sustentada no diálogo entre os estados membros. Por outro lado, também referimos como a União Europeia se confronta com a dificuldade da sua própria (re)construção, a que não é a alheia a influência diferencial dos estados membros e dos princípios de cidadania que os norteiam. No período atual, a União Europeia parece atravessar uma fase de desestruturação e de potencial de fragilização da cidadania Europeia com consequências ao nível nacional e europeu.

Para compreendermos melhor esta questão, analisamos documentos a nível nacional e europeu sobre cidadania nacional e europeia no momento atual, na (UE) que permitiram identificar algumas das dimensões percepcionadas como essenciais para a construção de cidadania. Se por um lado esses documentos enfatizam o facto de menos estado social ter como resultado uma escola mais desigual; enfatizam também a necessidade de uma educação para a cidadania na Europa, que implica a construção da cidadania nacional e da cidadania europeia; e delineiam ainda caminhos para atingir justiça social na UE e mais além.

Temos em consideração a pertinência da construção de cidadania pela população jovem em ambientes educativos formais, nomeadamente, a escola, e os desafios confrontados por jovens com diferentes origens socio culturais e étnicas. A análise trouxe à evidência que, em tempo de crise, no contexto português, a falta de investimento nesta área pode por em risco o desenvolvimento pelos jovens da literacia política necessária ao exercício da cidadania nacional e europeia. Isto quer dizer que a omissão da educação para a cidadania mitiga o acesso da população jovem ao conhecimento e compreensão de factos básicos e conceitos essenciais que permitiriam o exercício de uma cidadania ativa, com voz e participação. O desenvolvimento de espírito crítico e de competências analíticas, que permitiriam a construção crítica de valores, atitudes e comportamentos baseados no reconhecimento, parecem poder também ser atenuados por esta falha na educação.

Caberia, no entanto, à escola democrática contribuir para uma sociedade também ela, democrática, solidária e com políticas que assegurassem a construção e desenvolvimento da cidadania nacional e europeia, de modo a permitir às e aos sujeitos jovens integrar-se, respeitar-se e reconhecer a diferença em si e no/a outro/a como maisvalia.

Sustentamos que é na pluralidade de pensamentos e de vozes que a cidadania nacional e europeia podem ser construídas, numa perspectiva complementar e de ruptura com a reprodução histórica das desigualdades educacionais e sociais. O caminho é sinuoso, contudo, quando trilhado pode trazer para as pessoas jovens nas sociedades europeias e ao nível global, (re)conhecimento, inclusão e justiça social.

\section{Referências}

ANSION, Juan; TUBINO, Fidel (Eds.). Educar em Ciudadanía Intercultural: Experiencias y retos en la formación de estudantes universitarios indígenas. Perú: Fondo Editorial de la Pontificia Universidad Católica del Perú, 2007.

ARAR, Khalid Husny. Leadership for Equity and Social Justice in Arab and Jewish Schools in Israel: Leadership Trajectories and Pedagogical Praxis. International Journal of Multicultural Education, 17(1), 2015, p.162-187.

ARAÚJO, Helena Costa. Cidadania na sua polifonia - Debates nos estudos de educação feministas. Educação, Sociedade e Culturas, 25, 2007, p.83-116.

ARNOT, Madeleine. Educating the Gendered Citizen: Sociological Engagements with National and Global Agendas. London and New York: Routledge, 2009. 
BENAVENTE, Ana \& PEIXOTO, Paulo (Coord.). Menos Estado Social, uma Escola mais Desigual. CES; UC; CeiEF; ULHT: Observatório de Políticas de Educação e de Formação, 2015.

BERKOVICH, Izhak. A socio-ecological framework of social justice leadership in education. Journal of Educational Administration, 52(3), 2014, p. 282-309. DOI: 10.1108/JEA-12-2012-0131.

COM. Communication from the Commission - Europe 2020: A strategy for smart, sustainable and inclusive growth. Brussels: European Comission, 2010. Disponível em: $<$ http://ec.europa.eu/eu2020/pdf/COMPLET\%20EN\%20BARROSO\%20\%20\%20007 \%20-\%20Europe\%202020\%20-\%20EN\%20version.pdf>. Retirado em: 1 fev. 2016.

COM (European Commission). Strategic framework for education and training, 2010.

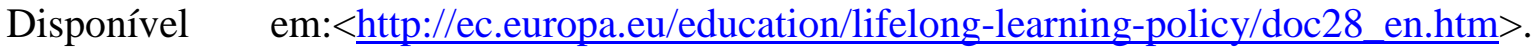
Retirado em: 12 out. 2009.

COMISSÃO EUROPEIA. Como funciona a União Europeia - Guia das Instituições da União Europeia, 2013.2 Disponível em:https://infoeuropa.eurocid.pt/files/database/000051001-000052000/000051475.pdf.

Retirado em: 10 set. 2016.

COUNCIL OF EUROPE. White Paper on Intercultural Dialogue: Living Together As Equals in Dignity. Strasbourg: Ministers of Foreign Affairs, 2008. Disponível em: <http://www.coe.int/t/dg4/intercultural/whitepaper_interculturaldialogue_2_EN.asp >.

Retirado em: 1 maio. 2015.

DECRETO-LEI n. ${ }^{\circ} 139 / 2012$ de 5 de julho. Disponível em: <https://dre.pt/application/dir/pdf1sdip/2012/07/12900/0347603491.pdf $>$. Retirado em 11 jun. 2015.

DECRETO-LEI n. ${ }^{\circ} 91 / 2013$ de 10 de julho. Disponível em: < http://www.dge.mec.pt/sites/default/files/Basico/Legislacao/dl_91_2013_10_julho.pdf>.

Retirado em 22 fev. 2016.

EURYDICE. A Educação para a Cidadania na Europa. Lisboa: Direção-Geral de Estatísticas da Educação e Ciência, 2012. Disponível em: $\langle$ http://eacea.ec.europa.eu/education/eurydice $>$. Retirado em: 20 fev. 2015. Doi: $10.2797 / 21471$.

FREIRE, Paulo. Pedagogia do oprimido. Rio de Janeiro: Paz e Terra, 2002.

KEATING, Avril. Educating Europe's citizens: moving from national to post-national models of educating for European citizenship. Citizenship Studies 13(2), 2009, p.135-151. DOI: $10.1080 / 13621020902731140$.

LEITE, Carlinda; FERNANDES, Preciosa \& SILVA, Sofia Marques da. O lugar da educação para a cidadania no sistema educativo português: perspetivas de docentes de uma escola TEIP. Educação 36(1), 2013, p.35-43. Disponível em: <file:///C:/Users/ciie/Downloads/12297-49822-1-PB.pdf>. Retirado em: 8, jun. 2014.

LEMOS, Flávia; CRUZ, Franco \& SOUSA, Giane. Práticas educativas, linguagens e produção da diferença. Dialogia, São Paulo, 20, 2014, p.231-242, jul./dez. DOI: 10.5585/Dialogia.n20.4724. 
MACEDO, Eunice. Os Rankings, por outro lado... Possibilidades de cidadania jovem, na tensão da mudança educativa e social. Tese de doutoramento. Porto: FPCEUP, 2011.

MACEDO, Eunice \& ARAÚJO, Helena Costa. Young Portuguese construction of educational citizenship: commitments and conflicts in semi-disadvantaged secondary schools. Journal of Youth Studies, 17(3), 2014, p.343-359.

MACEDO, Eunice, ARAÚJO, Helena C., MAGAlHÃES, António M., \& ROCHA, Cristina. La construcción del abandono temprano de la escuela como concepto político: Un análisis en la sociología de la educación. Profesorado: Revista de Curriculum y Formación del Profesorado, 19(3), 2015, p. 28-42.

MACEDO, Eunice \& FERREIRA, Pedro (Eds.). Construindo Pilares do Projeto Europeu com Jovens nas Escolas: Informação, Reflexão e Ação. Porto: CIEJD - Centro de Informação Europeia Jacques Delors \& CIIE, 2014.

MANTU, Sandra. Concepts of Time and European Citizenship. European Journal of Migration and Law, 15, 2013, p.447-464.

MEIER, Petra \& LOMBARDO, Emanuela. Concepts of citizenship underlying EU gender equality policies. Citizenship Studies, 12(5), 2008, p.481-493.

NÓVOA, António. L'Europe et l'éducation: Éléments d'analyse socio-historique des politiques éducatives européennes. In WINTHER-JENSEN, T. (Ed.). Challenges to European education: Cultural values, national identities, and global responsibilities. Sonderdruck: Peter Lang, 1996, p.29-79.

OLIVEIRA, Lilian \& LIMA, Paulo. Cidadania e educação enquanto valor económico: por uma perspectiva diferenciada. Revista HISTEDBR On-line, 54, 2013, p. 89-99.

OLSEN, Espen. European Citizenship: Mixing Nation State and Federal Features with a Cosmopolitan Twist. Perspectives on European Politics and Society, 14(4), 2013, p.505-519. http://dx.doi.org/10.1080/15705854.2013.772750.

PINTASILGO, Maria de Lourdes. Para um novo paradigma: um mundo assente no cuidado. Antologia de textos de Maria de Lourdes Pintasilgo. Porto: Edições Afrontamento, 2012.

PREUSS, Ulrich K; EVERSON, Michelle; KOENIG-ARCHIBUGI, Mathias \& LEFEBVRE, Edwige. Traditions of Citizenship in the European Union. Citizenship Studies, 7(1), 2003, p.3-14. http://dx.doi.org/10.1080/1362102032000048675.

RUSSO, Miguel Henrique. Gestão democrática, autonomia e projeto político-pedagógico: pressupostos da qualidade da educação. Dialogia, São Paulo, 19, 2014, p.67-78, jan./jun. DOI: 10.5585/Dialogia.n19.4988.

SANTOS, Boaventura de Sousa. Se Deus fosse um ativista dos Direitos Humanos. Almedina, 2014.

STOER, Stephen. Novas formas de cidadania, a construção europeia e a reconfiguração da universidade. Educação, Sociedade \& Culturas, 26, 2008, p.219-238.

SCHRAAD-TISCHLER, Daniel. Social Justice in the UE - Index Report 2015. Social Inclusion Monitor Europe. Berlin, 2015.

YOUNG, Iris. Justice and the politics of difference. Princeton: Princeton University Press, 1990. 


\section{YOUNG, Iris. Intersecting Voices - dilemmas of gender, political philosophy, and policy. Princeton: Princeton University Press, 1997.}

\section{Notas}

${ }^{1}$ Email: sarapinheiro@fpce.up.pt. Instituição: Centro de Investigação e Intervenção Educativas (CIIE) da Faculdade de Psicologia e de Ciências da Educação da Universidade do Porto (FPCEUP)

2 Email: eunice@fpce.up.pt. Instituição: Centro de Investigação e Intervenção Educativas (CIIE) da Faculdade de Psicologia e de Ciências da Educação da Universidade do Porto (FPCEUP)

3 Este estudo é financiado pela FCT (Fundação para a Ciência e a Tecnologia), com a referência: $\mathrm{PD} / \mathrm{BD} / 105705 / 2014$

${ }^{4}$ É de notar que, nos registos de 2014 do Serviço de Estrangeiros e de Fronteiras, a cidade do Porto, onde se realiza o estudo, conta com 8012 cidadãos/cidadãs de origem brasileira, um número que tem vindo a variar ao longo dos anos. [http://sefstat.sef.pt/distritos.aspx] - Retirado em março, 2016, 8.

${ }^{5}$ A LBSE, Lei n. ${ }^{\circ}$ 46/86, de 14 de outubro, foi produzida aquando da adesão de Portugal à então Comunidade Económica Europeia (CEE) e atual União Europeia (UE).

${ }^{6}$ Salienta-se que o direito a circular, estudar e trabalhar na UE surge pela introdução do conceito de cidadania na própria União Europeia. Em termos práticos, a CE concretiza-se, por exemplo, através da mobilidade entre cidadãos/ãs, possibilitando circular, estudar e trabalhar na UE "não podendo ser objeto de discriminação com base na sua nacionalidade, etnia, religião, idade, sexo e orientação sexual" (Macedo \& Ferreira, 2014:33), sendo estes direitos reforçados com o direito de residência aos membros da família, oriundos de outros países, mesmo que perante ausência de atividade laboral no país de integração.

${ }^{7} \mathrm{O}$ ensino básico, em Portugal, corresponde ao ensino fundamental, no Brasil.

Recebido: novembro/16 Aprovado: dezembro/16 